\title{
Serviceability analysis and increased axle load performance of heritage arch gallery railway bridge
}

Vinay Shimpi (Main Author)

Department of Civil Engineering, National Institute of Technology Puducherry

Karaikal, 609609, Puducherry (India)

vinay.nitpy@gmail.com

Madappa VR Sivasubramanian (Corresponding Author)

Department of Civil Engineering, National Institute of Technology Puducherry

Karaikal, 609609, Puducherry (India)

madappa@nitpy.ac.in

\section{S.B. Singh}

Department of Civil Engineering, Birla Institute of Technology and Science Pilani

Pilani, 333031, Rajasthan (India)

sbsingh@pilani.bits-pilani.ac.in

Manuscript Code: 21471

Date of Acceptance/Reception: 21.03.2021/20.09.2020

DOI: $10.7764 /$ RDLC.20.1.178

\section{Abstract}

This investigation deals with the serviceability analysis and increased axle load performance of Bridge No. 541 of UNESCO recognised Kalka Shimla Mountain Railways, which is a multi-storey arch gallery stone masonry bridge situated in the state of Himachal Pradesh, India. For this purpose, a finite element (FE) model was developed based on the drawings and reports available in Shimla Division, Northern Railways, India. Further, the results obtained from ambient vibration test (AVT) and operational modal analysis (OMA) is utilized to model update the initial FE model by modifying the mechanical properties of stone masonry. The serviceability against present-day axle loading (H Class Loading, Indian Railways) and present speed of the train is assessed. At last, a parametric study is conducted to understand the feasibility to attain higher speeds (up to $40 \mathrm{kmph}$ ) of the present axle load and higher axle load with different speeds of the train over the bridge to check the serviceability conditions advised in the Indian Railways code and also International codes. Finally, the study concluded that Bridge No. 541 of Kalka Shimla Mountain Railways can sustain speeds up to 40 kmph for current axle loading satisfying serviceability conditions.

Keywords: masonry arch bridge, heritage structure, moving load analysis, serviceability, ambient vibration test.

\section{Introduction}

India is a nation rich in cultural heritage, as evidenced by its tourism industry. Presently, Travel \& Tourism Competitiveness Report 2019 (Lauren Uppink Calderwood Maksim Soshkin, 2019) gave 34th rank to India out of 136 countries overall for the Travel \& Tourism Competitiveness Index which led to an increase in transport capacity demand. To meet the necessity of tourism, the transportation capacity of the railways should also be increased either in terms of axle load capacity or, in terms of the frequency of the trains with increased speeds. Indian railway is one of the largest railway networks in the World. There are about 1,27,768 bridges available in India out of which 19,647 are masonry arch bridges (IRICEN, 2009). Further, many of these bridges were constructed pre-independence era which is still in service. Table 1 shows some important bridges present in India.

\begin{tabular}{clll}
\multicolumn{3}{c}{ Table 1. Important bridges in Indian railways. (Self-Elaboration). } \\
\hline SI. №. & Name of the Bridge & Special Feature & Location \\
\hline 1 & $\begin{array}{l}\text { Bridge No. 13 on Tundla Agra } \\
\text { Section }\end{array}$ & $\begin{array}{l}\text { Largest span of masonry arch } \\
\text { about } 27.43 \mathrm{~m}\end{array}$ & Agra railway section \\
& $\begin{array}{l}\text { Bridge No. 208 on Howrah } \\
\text { Burdhawan mainline }\end{array}$ & $\begin{array}{l}\text { Longest arch bridge about } \\
\text { B54.9m }\end{array}$ & Howrah railway section \\
& $\begin{array}{l}\text { Bridge No. 541 on Kalka Shimla } \\
\text { Mountain railway line }\end{array}$ & Arch gallery 4 storied bridge & Kalka-Shimla railway line \\
& & & \\
\hline
\end{tabular}

These bridges were designed and constructed for olden day wheel axle loads adopting empirical formulas. However, the serviceability analyses need to be performed against increased axle loads and various train speeds to check the safety and performance of these bridges towards future services and preservation. Fanning and Boothby (2001) developed a finite element (FE) model based on modal analysis and field study. They recommended that model mesh 
and material properties are important parameters for the development of reliable FE model. Brencich and Sabia (2008) investigated an 18-span arch bridge by dynamic tests and a reliable FE model was prepared. The study revealed that the developed FE model can give accurate bridge response under service load conditions. Bayraktar et al. (2010) developed a Frequency domain operational modal analysis (OMA) procedure to estimate the natural frequency, mode shape and damping ratio for masonry arch bridges. Banerji and Chikermane (2012) developed a sustainable FE model updating procedures for 75-year-old masonry arch bridge and validated the developed procedures which can be utilized for any existing masonry arch bridges for assessment.

Kishen et al. (2013) conducted a field study and developed a numerical model under static loads. Moreover, the numerical simulations were performed to understand the response of the bridge for increased axle loads. De Santis and De Felice (2014) investigated the load-carrying capacity and safety factor for masonry arch bridge utilizing fiber beam based model approach. The study showed that the approach is reliable for understanding the limited parameters of the masonry arch bridge. Ataei et al. (2016) investigated the safety of an old railway masonry arch bridge, by conducting visual inspection and dynamic loading testing, and studied the possibility of increasing axle load of the bridge. The study concluded that the bridge can sustain higher axle loads. Ataei et al. (2017) investigated experimental and analytical natural frequencies for model verification of a masonry arch bridge. Using the calibrated model, the bridge was assessed for safety in serviceability and ultimate limit states due to the application of higher axle loads.

Boothby (2001) investigated the serviceability behaviour of the masonry arch bridge through quasi distributed sensing techniques to quantify the dynamic response of the bridge through the measurement of strains and displacement. Dhanasekar et al. (2019) performed a serviceability assessment of the masonry arch bridge utilizing digital image correlation techniques and developed a reliable numerical model. The study concluded that the predicted strains from a numerical model had good correlation with the field measurements. Tubaldi et al. (2020) performed a parametric study on the masonry arch bridges to find variation in stiffness and ultimate load-carrying capacity using a mesoscale numerical model. The study provided useful information regarding risk assessment and important parameters which are affecting the behaviour of the bridge. Further, a comprehensive review on assessment procedures for masonry arch bridge can be seen in the literature (Consuegra \& Santos, 2015; Sarhosis, De Santis, \& de Felice, 2016; Shimpi, Sivasubramanian, \& Singh, 2019).

The present study assesses Bridge No. 541 of Kalka Shimla Mountain Railways for its serviceability for present-day loading as well as check the performance of the bridge for increased axle loads and increased speeds of the trains. For this purpose, a reliable FE model is developed and updated with the field results obtained from ambient vibration test (AVT) and operational modal analysis (OMA) of the bridge. The FE model update is performed by modifying the mechanical parameters of the stone masonry so that the dynamic response of the FE model can match with the field results in terms of natural frequency and mode shapes. At first, the developed model is utilized to study the serviceability of the bridge for present $\mathrm{H}$ Class Loading from a speed range of $10 \mathrm{kmph}$ to $40 \mathrm{kmph}$. Further, the performance of the bridge is analysed for modified meter gauge loading for speeds between $10 \mathrm{kmph}$ to $40 \mathrm{kmph}$. The results are compared with the indian railways codes and International codes for the safety limits in terms of deflection and acceleration values, respectively. Finally, conclusions are made regarding serviceability and performance of the bridge for increased axle loads as well as the critical speeds of the train on the bridge.

Description of the problem

\section{Description of the bridge}

The Kalka Shimla mountain railway was commissioned in the year 1903 for public traffic. It is a hill passenger railway connecting Kalka station and Shimla station having the length of about $96.6 \mathrm{~km}$ at an altitude more than $2000 \mathrm{~m}$ from mean sea level on the Himalayas located in the state of Himachal Pradesh, India. Also, the rail network holds the Guinness Book of World Records for its 800 bridges \& 103 tunnels in the mountain region (Mathur, 2008). In the year 2008, it was listed in "Mountain Railways of India” and recognized as world heritage site by UNESCO (ICOMOS, 2008 ). The main features of the Kalka Shimla mountain railway line are stone masonry bridges with the absence of girders. There are a total of 42 major bridges which are constructed as multi-arched galleries like ancient Roman Aqueducts. Bridge No. 493 and Bridge No. 541 are the most spectacular and complex bridges of this railway line.

Bridge No. 541 is located near Kanoh railway station at an altitude of $1650 \mathrm{~m}$ from mean sea level. This bridge is the tallest bridge amongst all the bridges in Kalka Shimla mountain railways, having a total height of $23.8 \mathrm{~m}$. The total length of the bridge is $52 \mathrm{~m}$ and situated at the reverse curve of $48^{\circ}$. The bridge is constructed as ashlar masonry of the limestone blocks joined with the lime mortar. The geometric details of Bridge No. 541 are given in Figure 1. 
A comprehensive visual survey is carried out to investigate the present-day condition of the bridge. At first, it is observed that some of the bridge elements are suffering from environmental, chemical and physical actions. It was observed that the stone blocks in the bridge have efflorescence, vegetation and water flowing. In some areas, mortar patches are observed to fill the joints. In the bottom of the bridge and near the abutments, landfills are observed. Further, minor patch works on the piers are spotted during the survey which depicts the presence of minor cracks in the stone masonry. It is observed that the bottom of the piers are resting on very hard rocky strata. Figure 2 shows images of the bridge for present-day condition.

Figure 1. Description of Bridge No. 541, Kalka Shimla mountain railways: a) bridge No. 541, Kalka Shimla montain railways; b) Plan; c) Elevation. (Self-Elaboration).
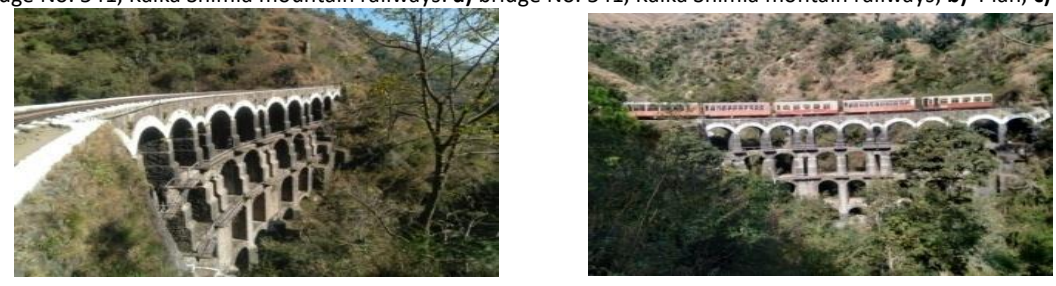

a)

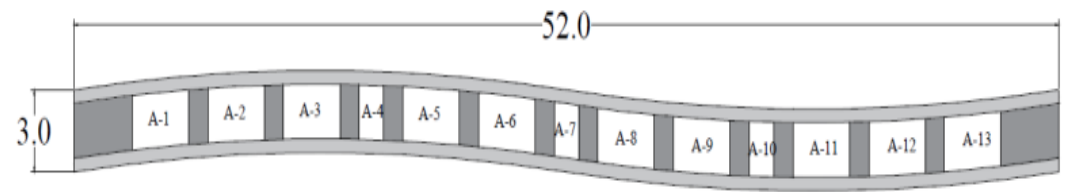

b)

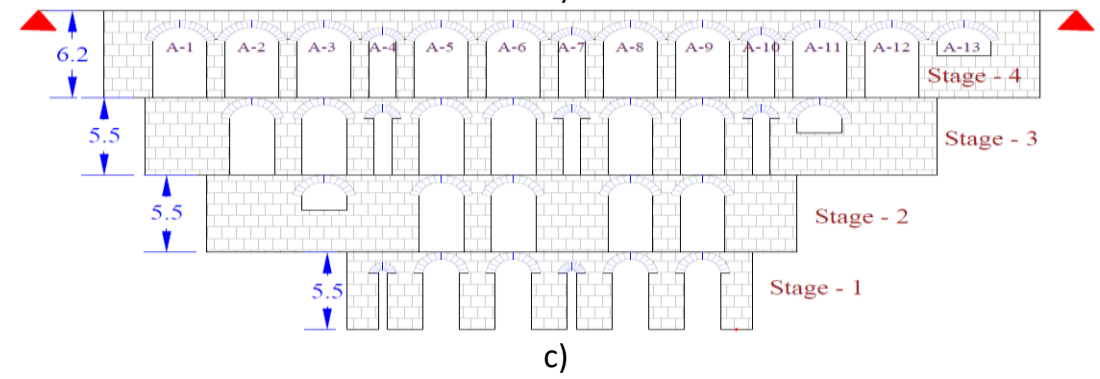

Figure 2. Present condition of Bridge No. 541, Kalka Shimla mountain railways: a) patches on the pier; b) bottom piers covered with the soil; c) efflorescense. (SelfElaboration).

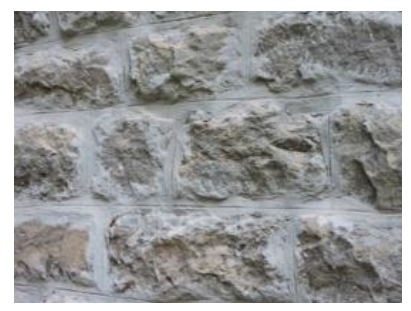

a)

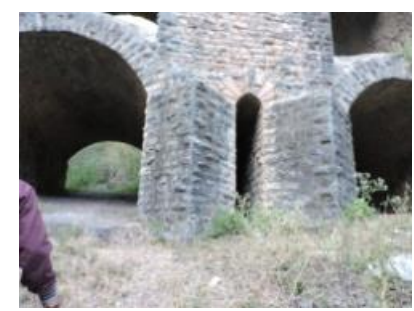

b)

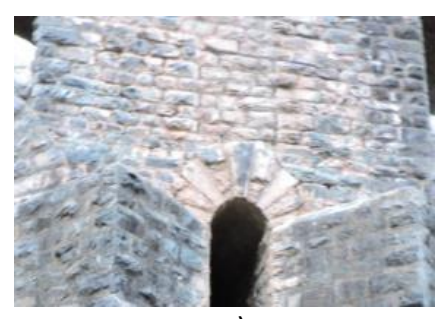

c)

Experimental method

\section{Experimental study on the bridge}

Ambient vibration test (AVT) is a field procedure adopted for the estimation of dynamic parameters of the structure. It is a non-destructive technique preferred for assessing the heritage structures for system identification (Shimpi et al., 2019). Due to advances in electronic instrumentation AVT have become most reliable field testing method for assessing the heritage structures. AVT is utilized by many researchers for assessing the different parameters of the heritage structures. Gentile and Saisi (2011) investigated the present-day condition of Pederno iron arch bridge (located in Italy) by performing AVT. The study concluded that AVT is an effective tool for structural health monitoring of heritage bridge structure. Sevim et al. (2016) evaluated the effect of near fault and far fault ground motion on the historical arch bridge. The study performed AVT on the structure and updated the numerical model based on AVT results. Roselli et al. (2018) studied the Ponte delle torri bridge in Italy to understand the health condition of the bridge after the seismic sequences in Italy. Pedrosa et al. (2019) developed the strengthening strategy to repair the Portel road bridge in Coimbra. 
The study utilizes AVT for identification of the element present strength and reliability according to standards. There are various application of the AVT are available in the literature (Altunişik, Genç, Günaydin, Okur, \& Karahasan, 2018; Aytulun, Soyoz, \& Karcioglu, 2019; Bautista-De Castro, Sánchez-Aparicio, Carrasco-García, Ramos, \& González-Aguilera, 2019; Di Lorenzo, Formisano, Krstevska, \& Landolfo, 2019; Ozcelik, Yormaz, Amaddeo, Girgin, \& Kahraman, 2019; Shimpi et al., 2019; Sun \& Xu, 2020; Zonno, Aguilar, Boroschek, \& Lourenço, 2019). In the presented study, the natural frequency and mode shape of Bridge No. 541, Kalka Shimla mountain railways was estimated. The field testing activities were performed to extract the modal parameters of the bridge and utilized for model update of the FE model developed in ABAQUS FE environment.

\section{Ambient vibration testing on the bridge}

An 8-channel OROS make OR35 portable data acquisition system with the 24-bit resolution was used for the field tests. Four uniaxial accelerometers Meggitt Endevco made 41A19 were placed on the bridge in different configurations to record the ambient dynamic response of the entire bridge under moving train excitation. In this study, the location for the accelerometer on the bridge is estimated by modal analysis of initial FE model developed on ABAQUS FE environment. The developed FE model is based on visual inspection, available drawings and data with Northern Railway and also using field measurements of the bridge. Because there were limited numbers of accelerometers and the cable lengths ranged from 10 to $30 \mathrm{~m}$ (the total length of the bridge is $52 \mathrm{~m}$ ), AVT of the whole bridge had to be done in multiple test setups. A total of 38 accelerometer locations were selected on the deck of the bridge to perform AVT as shown in Figure 3.

The green colour arrows showed the location of the roving accelerometer in the horizontal direction, blue colour square showed the position of the roving accelerometer in the vertically downward direction and red colour showed the position of the reference accelerometer which were kept stationary during the whole test. Further, each set comprises the two roving accelerometers and two reference accelerometers.

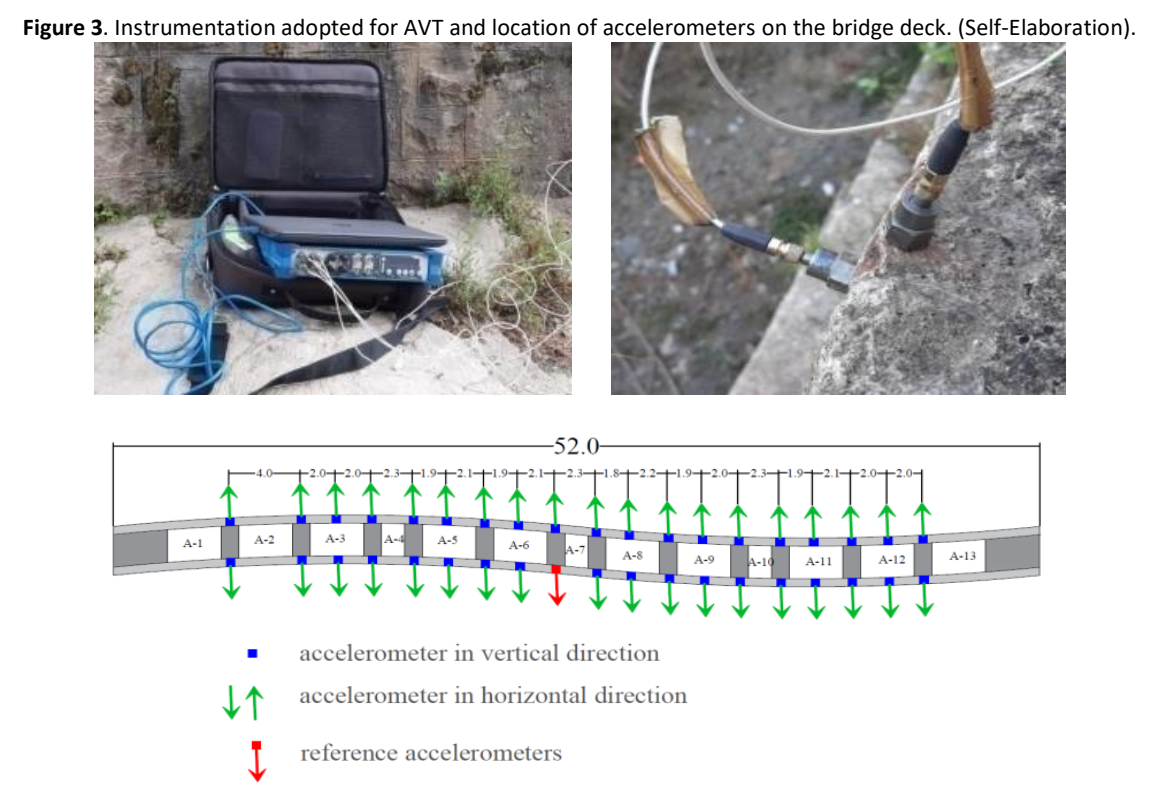

\section{Operational modal analysis}

The response signals from accelerometer were collected by the OR35 system was then converted from mechanical signals into digital signals and saved in computer device in the form of time history. OROS modal analysis software (OROS, 2018) was utilised for post-processing of the collected data. For the estimation of the modal parameters, OROS modal analysis software utilises frequency domain technique called Frequency Spatial Domain Decomposition (FSDD) (Zhang, Wang, \& Tamura, 2010). FSDD is the third generation of frequency-domain technique for modal parameter estimation. FSDD utilizes a unitary singular matrix to estimate the enhanced Power Spectral Density (PSD) through modal filtering. In this method mode shape can directly be obtained by singular vectors corresponding to maximum singular values located at the peaks of the mode indication function (MIF) plot which is derived based on spectrum decomposition of response PSD.

The response signal of the bridge is then post-processed in OROS modal analysis software and the Singular Value MIF with identified modes is presented in Figure 4. Three mode shapes and associated natural frequency of the bridge were 
determined through AVT and OMA. Figure 5 shows that first mode of the bridge is a transverse mode with natural frequency of $4.65 \mathrm{~Hz}$, the second mode was also transverse mode have natural frequency of $11.88 \mathrm{~Hz}$ and the first vertical mode was estimated at frequency $23.85 \mathrm{~Hz}$.

Figure 4. MIF plot with the identified mode shape of the bridge. (Self-Elaboration).

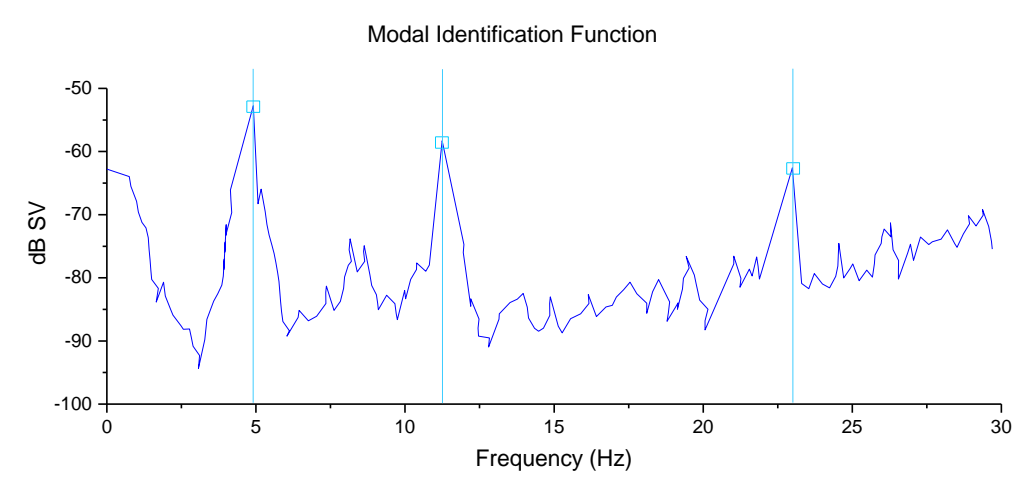

Figure 5. Experimental mode shapes estimated from AVT and OMA. (Self-Elaboration).

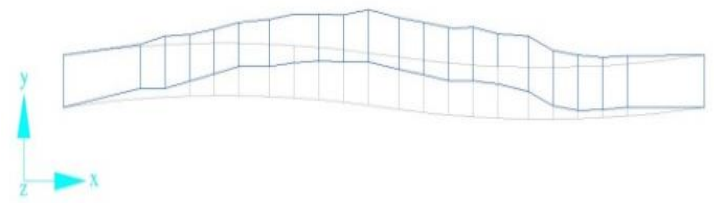

Mode 1 at $4.65 \mathrm{~Hz}$ at $\zeta=2.40 \%$

Mode 2 at $11.38 \mathrm{~Hz}$ at $\zeta=2.97 \%$

Mode 3 at $23.85 \mathrm{~Hz}$ at $\zeta=4.90 \%$

\section{Numerical modelling and updation}

The numerical model of Bridge No. 541 of Kalka Shimla mountain railways is developed in ABAQUS FE environment. The developed model is based on macro model strategy as suggested in the literature for large stone masonry structures (Milani, Casolo, Naliato, \& Tralli, 2012). This modelling technique is adopted due to its advantage for fast computational time over micro modelling strategy. As this study aims at the global response of the bridge due to the axle load, the local stress distribution between stone and mortar joint is not modelled. A homogenized model of the stone masonry is adopted for the assigning the material properties instead of modelling the stone mortar interface. The numerical model is developed based on the preliminary investigations conducted on the bridge. Firstly, visual inspection is performed on the bridge for locating damages. Then the measurements of the bridge are taken from the site for the different structural elements.

Also, documentation available at Shimla division, northern railway is collected and studied. It is to be noted that the bridge is UNESCO recognised World Heritage Site, this is why any kind of material testing is not conducted on the structure. A 3D model of the bridge is developed incorporating geometry of the bridge as shown in Figure 1 . Different structural elements like piers, arches, walls are identified in the bridge and modelled in ABAQUS. These elements are further connected using TIE constraints. The whole FE model of the bridge is presented in Figure 6 . Due to the absence of any material testing on the structure, the initial value of Young's modulus adopted for the stone masonry was 10,000 $\mathrm{MPa}$, density $2400 \mathrm{~kg} / \mathrm{m} 3$ and Poisson's ratio was kept 0.2 which is adopted from the literature (Bertolesi, Milani, Lopane, \& Acito, 2017; Fanning \& Boothby, 2001; Milani \& Lourenço, 2012). The bridge is located in a hilly region and it is assumed that the bridge is constructed on very hard and stiff strata. Hence, fixed boundary condition is chosen at the bottom and side of the bridge i.e. no translation and rotational displacements are allowed. 
In this study, the arches, piers and walls are modelled using standard linear C3D8R (8-node linear brick) element. The mesh size of the element plays an important role for estimation of accurate results. The coarser mesh can provide inaccurate results. In this study, a mesh convergence analysis is performed to determine the optimum mesh size. For this purpose, modal analysis is performed adopting different mesh sizes of the elements from $0.5 \mathrm{~m}$ at first and then reduced up to $0.1 \mathrm{~m}$. The results of the convergence analysis are presented in Figure 7, where change in the natural frequency of three modes is compared with the different mesh sizes. The mesh convergence analysis showed that the mesh size of $0.3 \mathrm{~m}$ can be adopted for estimating the accurate results considering the changes in the frequency are insignificant for finer mesh sizes. Moreover, finer mesh size of $0.2 \mathrm{~m}$ is also adopted at some locations, due to difficulty in adopting mesh size of $0.3 \mathrm{~m}$.

Finally, the total number of nodes and elements for bridge are 1,29,431 and 86,530, respectively. Furthermore, the program is run to estimate the dynamic properties of the bridges, for that modal analysis, is being run by Block Lancoz method as a method for modal extraction. After the analysis, modes found within a range of $4.10 \mathrm{~Hz}$ to $24 \mathrm{~Hz}$ for Bridge No. 541. The results of the modal analysis performed on the initial FE model is presented in Figure 8.
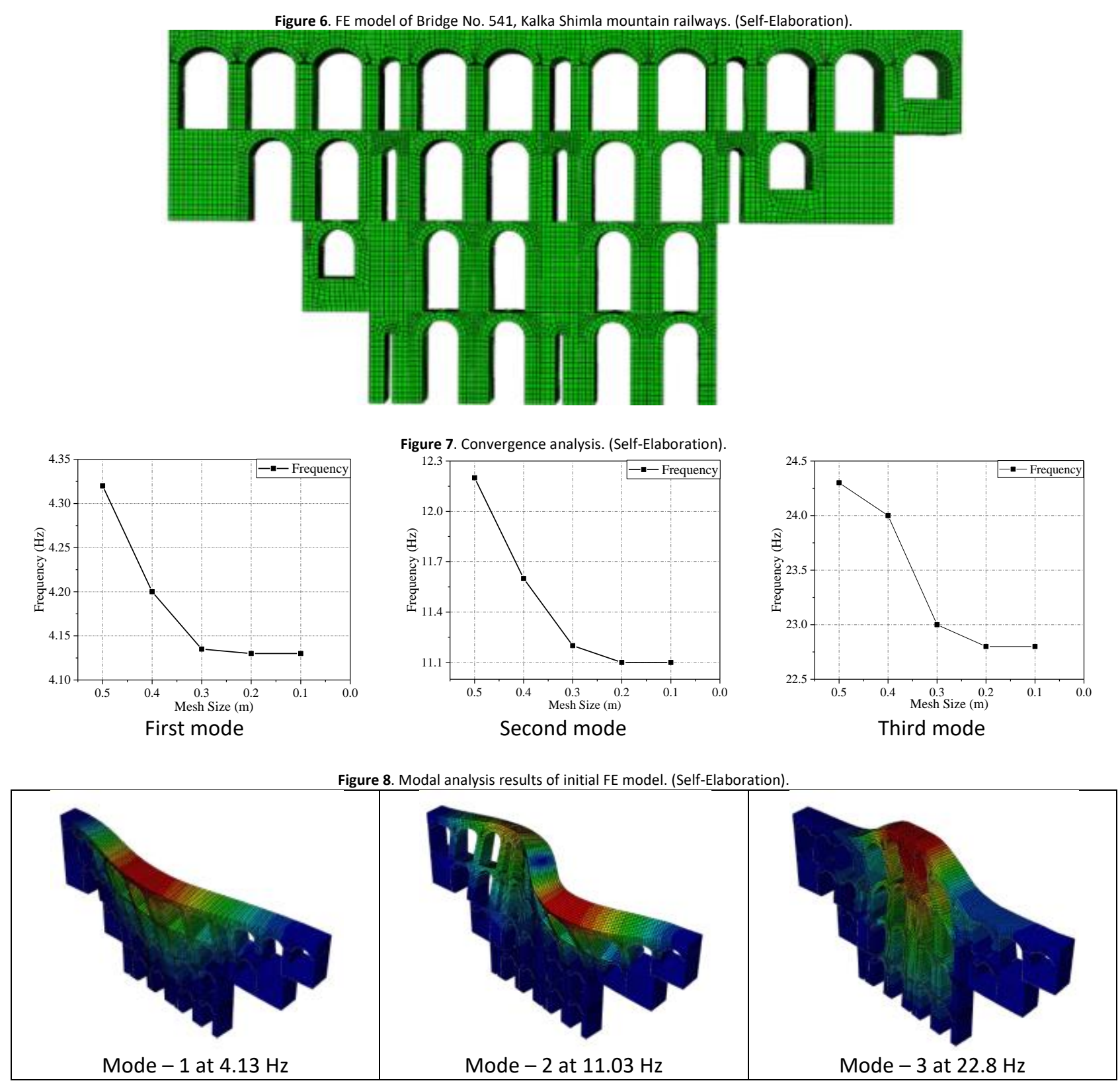

FE model updating

Finite element (FE) model updating is a procedure for calibrating the existing numerical model incorporating the results obtained from AVT and OMA. An existing FE model can account only the initial geometric and material properties. Perhaps in the case of a heritage structure, it becomes at most necessary to update the numerical model regularly for 
present-day condition towards accurate analysis. In general, FE model updating can be achieved by adjusting the physical properties, mechanical properties, boundary conditions, masses, restrained properties, joint properties and geometry of the elements in the numerical model to match against the results obtained from AVT and OMA.

In the primary investigation on the bridge, it is found that the bridges are fully intact. The boundary conditions opted for the numerical models are based on the observations made during primary survey of the bridges which is well discussed in section 2. Further, it is observed that the numerical mode shapes are in correlation with the experimental mode shapes. Thus, for calibration of numerical models, values of mechanical properties of stone masonry are modified for matching the natural frequency of FE models with the experimental results. The modified values of mechanical properties of stone masonry are presented in Table 2. Further, a comparison of initial natural frequency and modified natural frequency of FE models are shown in Table 3. The updated model is further utilized for assessment of presentday serviceability and performance for increased axle load analysis.

\begin{tabular}{llcc}
\multicolumn{4}{c}{ Table 2. Comparison of initial material property and updated material property. (Self-Elaboration). } \\
\hline Material & Parameter & Initial value & Updated value \\
\hline \multirow{2}{*}{ Stone Masonry } & Young's modulus $(\mathrm{GPa})$ & 10 & 9.6 \\
& Density $\left(\mathrm{kg} / \mathrm{m}^{3}\right)$ & 2,500 & 2,200 \\
\hline
\end{tabular}

Table 3. Comparison of the natural frequency of mode shape from the initial FE model, experimental values and updated FE model. (Self-Elaboration).

\begin{tabular}{lccccc}
\hline Modes & \multicolumn{4}{l}{ Natural Frequency $(\mathrm{Hz})$} & \\
\cline { 2 - 6 } & $\begin{array}{l}\text { Experimental } \\
\text { Results }\end{array}$ & $\begin{array}{l}\text { Initial FE } \\
\text { model }\end{array}$ & \% error & $\begin{array}{l}\text { Updated FE } \\
\text { model }\end{array}$ & \% error \\
\hline Mode-1 & 4.65 & 4.13 & 11.18 & 4.52 & 2.79 \\
Mode-2 & 11.38 & 11.03 & 7.15 & 12.01 & 1.09 \\
Mode-3 & 23.85 & 22.8 & 4.40 & 24.03 & 0.75 \\
\hline
\end{tabular}

\section{Validation of updated FE model}

A field investigation is performed on the bridge for capturing the vertical acceleration response at arch A- 6 on the bridge under moving train load. For this purpose, an accelerometer was placed in the middle of A-6 in vertical downward direction which present as a blue colour mark in Figure 9. Further, the acceleration in vertical direction at the middle of arch A-6 is recorded when a train with ZMD-3, B-B type locomotive (four axles with 8.90-ton axle load) with the seven bogies ( 4 axles) attached to it was allowed to move on bridge at a speed of $10 \mathrm{kmph}$. Figure 12 shows the recorded acceleration time history experienced at the middle of arch A-6. The RMS value of the acceleration estimated to 0.3 $\mathrm{m} / \mathrm{s}^{2}$ at the middle of arch A-6.

Figure 9. Accelerometer location of the bridge deck for the field investigation. (Self-Elaboration).

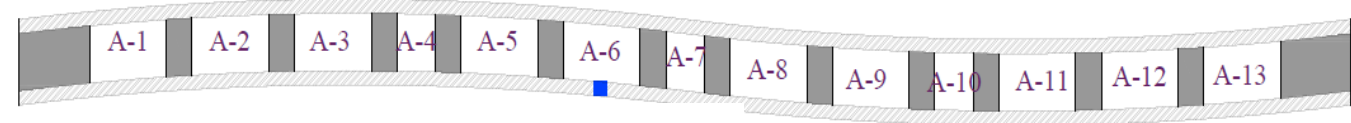

Accelerometer

To validate the updated FE model, dynamic implicit analysis is performed for a moving load on the whole bridge. In the analysis, B-B H Class Loading prescribed by the Indian Railway Code (RDSO, 2008) (see Figure 10) is applied, to simulate the present field condition. The effect of each axle load on a node is also carefully incorporated in the present analysis as described by Kaliyaperumal et al. (2011) based on the speed of the moving load (as shown Figure 11). Further, the structural damping of $4.90 \%$ is utilized in simulation which is based on the first vertical modal frequency of the bridge. Figure 12 presents the acceleration response at the middle of the arch A-6 for both experimental as well as dynamic analysis. The numerical RMS acceleration value at the middle of the arch A-6 for dynamic analysis is found to be 0.29 $\mathrm{m} / \mathrm{s}^{2}$ which is in close agreement with the field measurement value i.e. $0.30 \mathrm{~m} / \mathrm{s}^{2}$. Hence, the developed FE numerical model is found to be reliable for further investigations. 


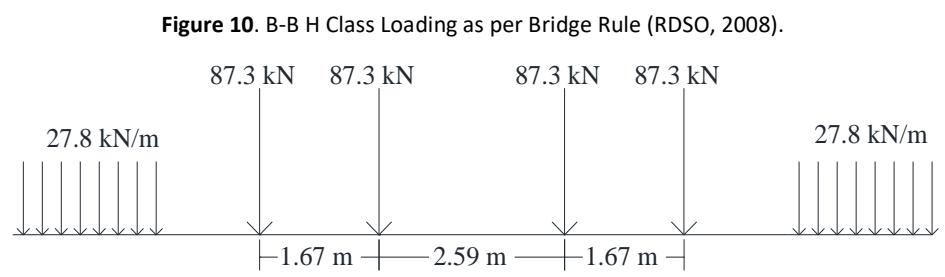

Figure 11. Effect of each axle load on the node (Kaliyaperumal et al., 2011).

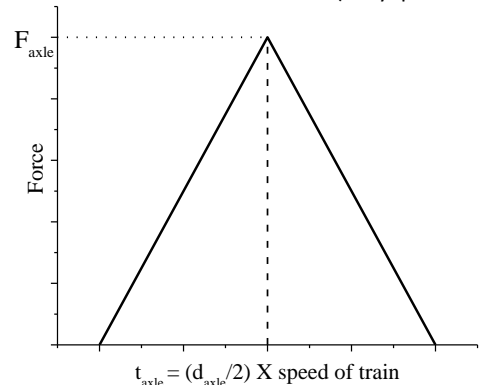

Figure 12. Comparison of acceleration response of field study and dynamic analysis. (Self-Elaboration)

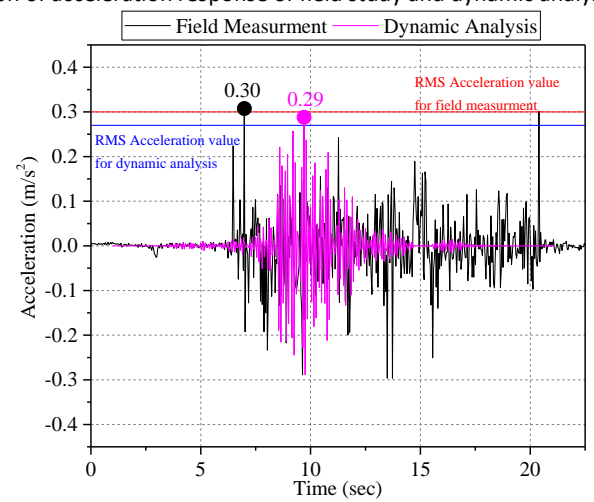

\section{Serviceability and increased axle load analysis}

Using the validated FE model, the present investigation made an attempt in understanding the serviceability and performance of the bridge against increased axle load with varying the speeds of the train. For this purpose, two types of axle load patterns 1) 15.9-ton BO-BO Modified Meter Gauge (MMG) Loading and 2) 15.9-ton CO-CO Modified Meter Gauge Loading prescribed in Bridge Rule, Indian Railways (RDSO, 2008) (shown in Figure 13) are considered for the analysis. Furthermore, a parametric study is also conducted for estimating the critical speed of the trains on the bridge. For this purpose, three locomotive load patterns as mentioned are moved on the bridge from one end to other end with the speed of $10 \mathrm{kmph}, 20 \mathrm{kmph}, 30 \mathrm{kmph}$ and $40 \mathrm{kmph}$.

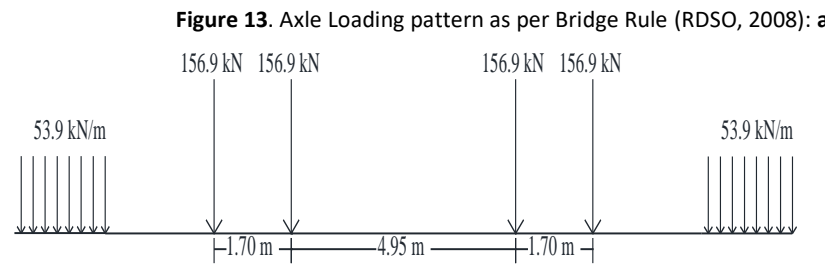

a)

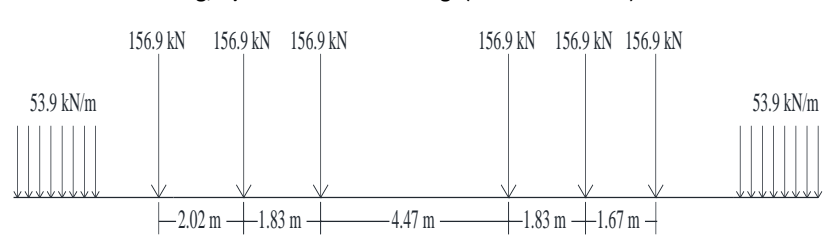

b) 


\section{Deflection of the bridge arches}

Figure 14 shows the deflection at the crown of the different arches of the bridge for different loadings and speeds of the train. The deflection plot shows that the deflection at the crown of A-6 is higher than that of other arches for all types of load pattern. Further, it can be noticed that the deflection at the speed of $20 \mathrm{kmph}$ is slightly higher than that of for other speeds. According to the Indian Code (RDSO, 1962) the criteria for the safe load is:

Deflectiond $<0.75+\frac{(L-1)(1.25-0.75)}{3.75}$ for span more than $1 \mathrm{~m}$ to span less than $4.5 \mathrm{~m}$.

here, $L$ is the span length of the arch which is equal to $3.5 \mathrm{~m}$ in the case of A-6.

According to Indian code, the permissible limit of the deflection at the crown is $1.08 \mathrm{~mm}$ for the A-6 arch. Figure 15 shows the maximum deflection at the crown of $A-6$, which is $0.79 \mathrm{~mm}$ at a speed of $20 \mathrm{kmph}$ for BO-BO MMG Loading. Hence, the bridge is safe for all three loading patterns. The defection due to present loading that is B-B H Class Loading is very less as compared to other two loadings. Further, American Railway Engineering and Maintenance-of-Way Association (AREMA, 2008) recommends that the maximum deflection of the bridge from the live load should not exceed the value of $\mathrm{L} / 640$. For the studied bridge maximum deflection limit value calculated is $5.4 \mathrm{~mm}$ which is much greater than $0.79 \mathrm{~mm}$. Hence, the bridge also met the requirement of deflection as per AREMA code.

Figure 14. Deflection response at the mid of the arches A-5, A-6, A-8 and A-9 due to different moving loads at different speeds: a) deflection responde due to B-B-H class loading; b) deflection responde due to BO-BO MMG loading; c) deflection response due to CO-CO MMG loading. (Self-Elaboration).

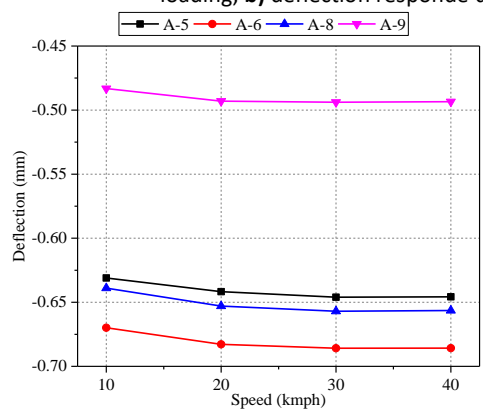

a)

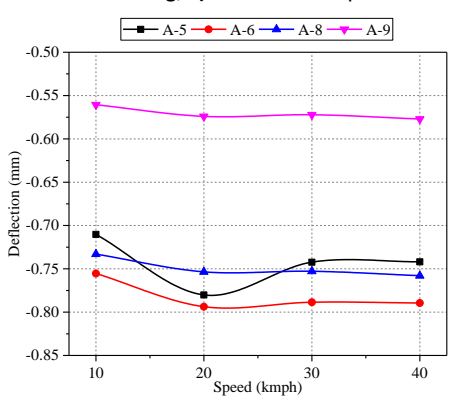

b)

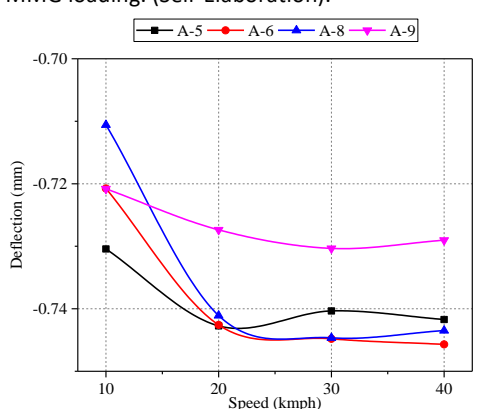

c)

Figure 15. Deflection response of A-6 due to different loading moving with different speed. (Self-Elaboration).

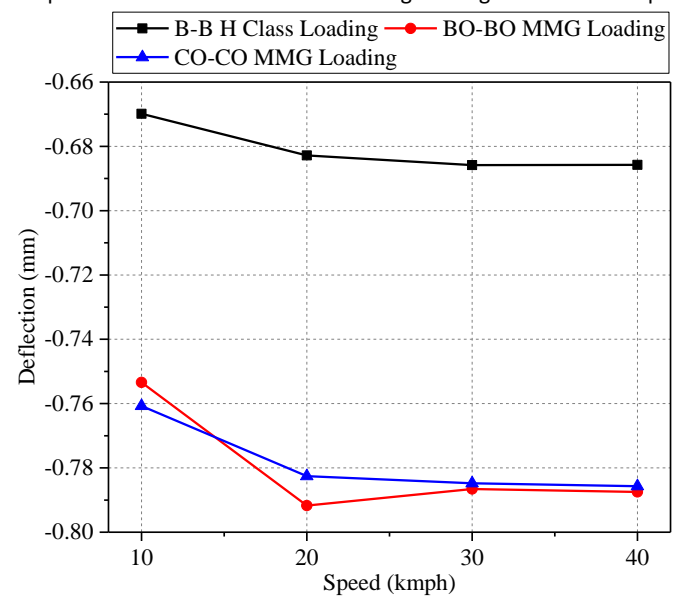

\section{Dynamic amplification factor (DAF)}

Dynamic amplification factor (DAF) is considered a very important parameter to assess the serviceability of the bridge under dynamic loading. Generally, DAF is an estimate of the dynamic response of the bridge under moving loading. DAF is calculated from the formula suggested by Kwark et al. (2004):

$$
\text { DAF }=\frac{\text { Deflection of the crown due to dynamic loading }}{\text { Deflection of the crown due to static loading }}
$$


For the estimation of DAF, the maximum deflection at the crown of different arches of the bridge was considered in the present study. The estimated DAF value for different loadings and varying speeds are presented in Figure 16 . Further, the calculated DAF values for present-day loading are noticed to be lesser than that of values estimated by Eurocode (CEN, 2003) and AREMA (AREMA, 2006). It is also noticed that the BO-BO MMG Loading and CO-CO MMG Loading on A-6 arch with the speed of $20 \mathrm{kmph}$ to $40 \mathrm{kmph}$ are having DAF values more than that of estimated by Eurocode (CEN, 2003) and AREMA (AREMA, 2006). Further, the DAF value for all three axle loadings is within the limit of Eurocode (CEN, 2003) and AREMA (AREMA, 2006) for speed $10 \mathrm{kmph}$ for all the arches.

Figure 16. DAF value for different position in the bridge and different International codes: a) DAF for A-5 arch; b) DAF for A-6 arch; c) DAF for A-8 arch; d) DAF for A-9 arch. (Self-Elaboration).

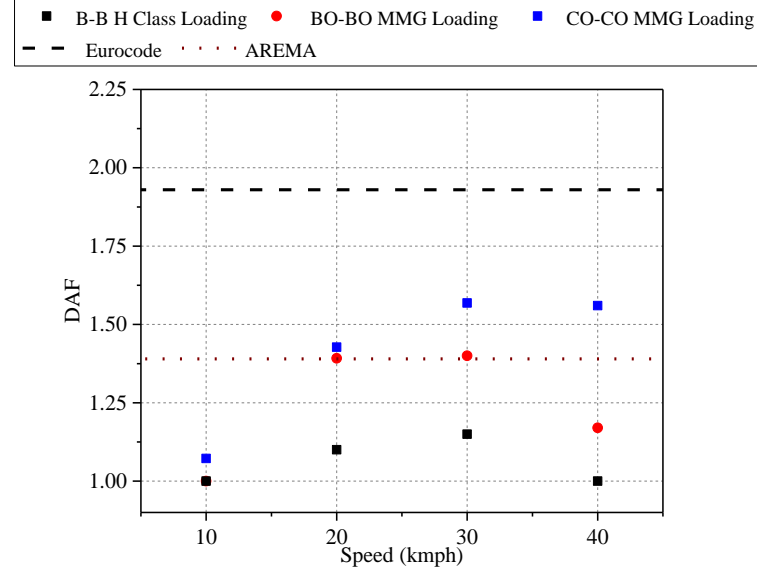

a)

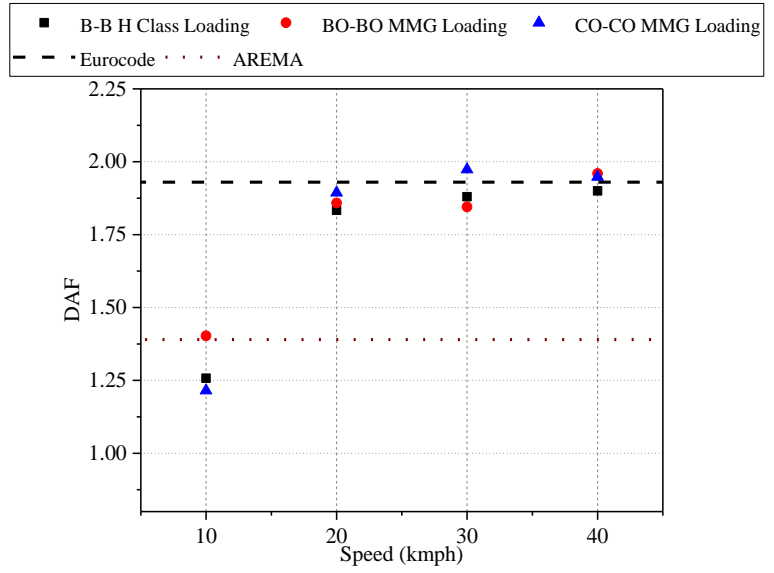

c)

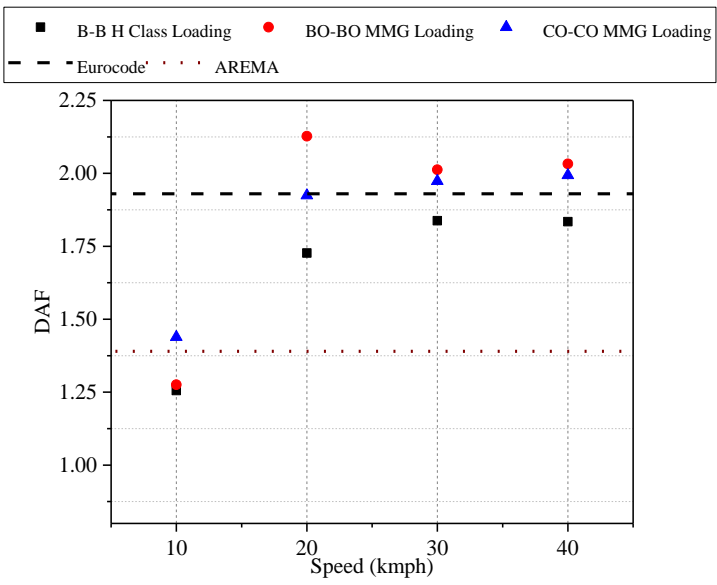

b)

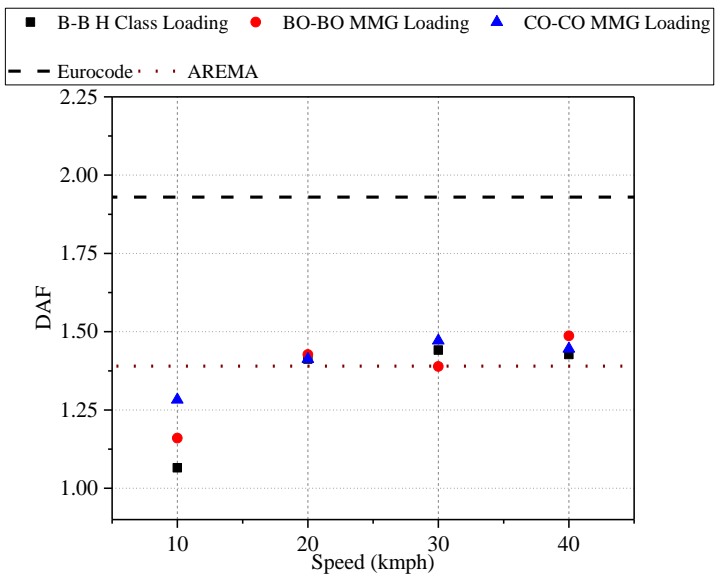

d)

Conclusions

The present study investigated the serviceability and performance of a 100-year-old multiple arch gallery bridge (Bridge No. 541 of Kalka Shimla Mountain Railway, India). In the study, a FE model was developed and updated using the results obtained from AVT and OMA. Further, the updated model is utilized to study the serviceability and performance of the bridge for three-axle load patterns adopting different speeds between $10 \mathrm{kmph}$ to $40 \mathrm{kmph}$. For this purpose, the deflection, DAF and acceleration response of different arches are the parameters utilized. Following are the conclusions drawn from the study:

- $\quad$ The study showed that a reliable FE model can be developed by adopting AVT and OMA. The updated model showed the same acceleration response at arch A- 6 as measured from the field measurement for the same axle load pattern which further confirms robustness of the updated FE model.

- While studying the serviceability, it is found that the deflection at the crown of the arches A-5, A-6, A-8 and A9 for B-B H Class Loading (which is presently deployed) is well within the safe limit as prescribed by the Indian Railway Code (RDSO, 1962) for speed range of $10 \mathrm{kmph}$ to $40 \mathrm{kmph}$. Further, the deflection limits for $B-B \mathrm{H}$ Class Loading were also checked against ARMA Code (AREMA, 2008), and the values found to be satisfied. Hence, the bridge is safe for present-day loading as per deflection criteria. 
- The estimated DAF values of the arches $A-5, A-6, A-8$ and $A-9$ for B-B $H$ Class Loading (which is presently deployed) is well within the limits prescribed by the Eurocode (CEN, 2003) and AREMA (AREMA, 2006). Additionally, the estimated DAF values showed that the bridge is experiencing higher dynamic response at $A-6$ arch for BO-BO MMG Loading and CO-CO MMG Loading between speed range of $20 \mathrm{kmph}$ to $40 \mathrm{kmph}$ which exceed the values prescribed by Eurocode (CEN, 2003) and AREMA (AREMA, 2006). Therefore, BOBO- MMG Loading and CO-CO MMG Loading may not be possible to deploy on the bridge with present strength.

Finally, this investigation concludes that the bridge has the capacity against increased speeds of present-day loading and the increased axle loads can be adopted with the restriction of the speed limit up to $10 \mathrm{kmph}$.

\section{Acknowledgement}

This paper is an outcome of the author's PhD research enrolled at National Institute of Technology Puducherry. Authors are thankful to the National Institute of Technology Puducherry for providing computational facilities. Further, authors acknowledge Northern Railways, Government of India for permitting to conduct the field study. Lastly, the authors are grateful to Shimla Division, Northern Railways, Government of India for providing accommodations and manpower throughout the field study.

\section{Funding}

This research study is sponsored by Seismology Division, Ministry of Earth Sciences, Government of India (Ref. No.: MoES/P.O.(Seismo)/1(296)/2016) sanctioned to Co-authors. The second author is the main supervisor of this study.

Altunişik, A. C., Genç, A. F., Günaydin, M., Okur, F. Y., \& Karahasan, O. S. (2018). Dynamic response of a historical armory building using the finite element model validated by the ambient vibration test. JVC/Journal of Vibration and Control, 24(22), 5472-5484. https://doi.org/10.1177/1077546318755559

AREMA. (2006). AREMA manual. American Railway Engineering and Maintenance-of-Way Association, Lanham, MD, USA.

AREMA. (2008). AREMA bridge inspection handbook. AREMA Committee 10.

Ataei, S., Jahangiri Alikamar, M., \& Kazemiashtiani, V. (2016). Evaluation of axle load increasing on a monumental masonry arch bridge based on field load testing. Construction and Building Materials, 116, 413-421. Retrieved from https://doi.org/10.1016/j.conbuildmat.2016.04.126

Ataei, S., Miri, A., \& Jahangiri, M. (2017). Assessment of load carrying capacity enhancement of an open spandrel masonry arch bridge by dynamic load testing. International Journal of Architectural Heritage, 11(8), 1086-1100. https://doi.org/10.1080/15583058.2017.1317882

Aytulun, E., Soyoz, S., \& Karcioglu, E. (2019). System Identification and Seismic Performance Assessment of a Stone Arch Bridge. Journal of Earthquake Engineering, ISSN: 1363-2469, 1-21. https://doi.org/10.1080/13632469.2019.1692740

Banerji, P., \& Chikermane, S. (2012). Condition assessment of a heritage arch bridge using a novel model updation technique. Journal of Civil Structural Health Monitoring, 2(1), 1-16. https://doi.org/10.1007/s13349-011-0013-9

Bautista-De Castro, Á., Sánchez-Aparicio, L. J., Carrasco-García, P., Ramos, L. F., \& González-Aguilera, D. (2019). A multidisciplinary approach to calibrating advanced numerical simulations of masonry arch bridges. Mechanical Systems and Signal Processing, 129, $337-365$. https://doi.org/10.1016/j.ymssp.2019.04.043

Bayraktar, A., Altunişik, A. C., Birinci, F., Sevim, B., \& Türker, T. (2010). Finite-Element Analysis and Vibration Testing of a Two-Span Masonry Arch Bridge. Journal of Performance of Constructed Facilities, 24(1), 46-52. Retrieved from https://doi.org/10.1061/(ASCE)CF.1943-5509.0000060

Bertolesi, E., Milani, G., Lopane, F. D., \& Acito, M. (2017). Augustus Bridge in Narni (Italy): Seismic Vulnerability Assessment of the Still Standing Part, Possible Causes of Collapse, and Importance of the Roman Concrete Infill in the Seismic-Resistant Behavior. International Journal of Architectural Heritage, 11(5), 717-746. Retrieved from https://doi.org/10.1080/15583058.2017.1300712

Boothby, T. E. (2001). Load rating of masonry arch bridge. Journal of Bridge Engineering, 6(2), 79-86. https://doi.org/10.1061/(ASCE)10840702(2001)6:2(79)

Brencich, A., \& Sabia, D. (2008). Experimental identification of a multi-span masonry bridge: The Tanaro Bridge. Construction and Building Materials, 22(10), 2087-2099. https://doi.org/10.1016/j.conbuildmat.2007.07.031

Eurocode C.E.N. (2003). Eurocode 1: Actions on structures-Part 2: Traffic loads on bridges. Brussels: European Standard EN, 2.

Consuegra, F. A., \& Santos, C. (2015). Vibration analyses for the local and global evaluation of bridges as a tool for structural retrofit. Revista de La Construccion, 14(1), 16-22. https://doi.org/10.4067/s0718-915x2015000100002

De Santis, S., \& De Felice, G. (2014). Overview of railway masonry bridges with a safety factor estimate. International Journal of Architectural Heritage, 8(3), 452-474. https://doi.org/10.1080/15583058.2013.826298 
Dhanasekar, M., Prasad, P., Dorji, J., \& Zahra, T. (2019). Serviceability Assessment of Masonry Arch Bridges Using Digital Image Correlation. Journal of Bridge Engineering, 24(2), 1-16. https://doi.org/10.1061/(ASCE)BE.1943-5592.0001341

Di Lorenzo, G., Formisano, A., Krstevska, L., \& Landolfo, R. (2019). Ambient vibration test and numerical investigation on the St. Giuliano church in Poggio Picenze (L'aquila, Italy). Journal of Civil Structural Health Monitoring, 9(4), 477-490. https://doi.org/10.1007/s13349-019-00346-7

Fanning, P. J., \& Boothby, T. E. (2001). Three-dimensional modelling and full-scale testing of stone arch bridges. Computers and Structures, 79(29-30), 2645-2662. https://doi.org/10.1016/S0045-7949(01)00109-2

Gentile, C., \& Saisi, A. (2011). Ambient vibration testing and condition assessment of the Paderno iron arch bridge (1889). Construction and Building Materials, 25(9), 3709-3720. https://doi.org/10.1016/j.conbuildmat.2011.04.019

ICOMOS. (2008). Kalka Shimla Railway ( India ) No 944 ter, ICOMOS, Paris, France.

IRICEN. (2009). Inspection, Assessment, Repairs and Retrofit of Masonry Arch Bridges. Pune Maharastra India, 411001: Indian Railway Institute of Civil Engineering.

Kaliyaperumal, G., Imam, B., \& Righiniotis, T. (2011). Advanced dynamic finite element analysis of a skew steel railway bridge. Engineering Structures, 33(1), 181-190. https://doi.org/10.1016/j.engstruct.2010.10.003

Kishen, J. M. C., Ramaswamy, A., \& Manohar, C. S. (2013). Safety assessment of a masonry arch bridge: Field testing and simulations. Journal of Bridge Engineering, 18(2), 162-171. https://doi.org/10.1061/(ASCE)BE.1943-5592.0000338

Kwark, J. W., Choi, E. S., Kim, Y. J., Kim, B. S., \& Kim, S. I. (2004). Dynamic behavior of two-span continuous concrete bridges under moving high-speed train. Computers and Structures, 82(4-5), 463-474. https://doi.org/10.1016/S0045-7949(03)00054-3

Lauren Uppink Calderwood Maksim Soshkin. (2019). The Travel and Tourism Competitiveness Report 2019. Geneva: World Economuc Forum. Available on: http://www3.weforum.org/docs/WEF_TTCR_2019.pdf

Mathur, V. N. (2008). Bridges, Buildings \& Black Beauties of Northern Railway: Glimpses of the Rich Heritage of India's Premier Railway. Institute of Rail Transport.

Milani, G., Casolo, S., Naliato, A., \& Tralli, A. (2012). Seismic assessment of a medieval masonry tower in Northern Italy by limit, nonlinear static, and full dynamic analyses. International Journal of Architectural Heritage, 6(5), 489-524. https://doi.org/10.1080/15583058.2011.588987

Milani, G., \& Lourenço, P. B. (2012). 3D non-linear behavior of masonry arch bridges. Computers and Structures, 110, 133-150. https://doi.org/10.1016/j.compstruc.2012.07.008

OROS. (2018). Modal Structural Solution Manual. OROS, Meylan, France.

Ozcelik, O., Yormaz, D., Amaddeo, C., Girgin, O., \& Kahraman, S. (2019). System Identification of a Six-Span Steel Railway Bridge Using Ambient Vibration Measurements at Different Temperature Conditions. Journal of Performance of Constructed Facilities, 33(2). https://doi.org/10.1061/(ASCE)CF.1943-5509.0001260

Pedrosa, B., Rebelo, C., Gervásio, H., \& da Silva, L. S. (2019). Modal Identification and Strengthening Techniques on Centenary Portela Bridge. Structural Engineering International, 29(4), 586-594. https://doi.org/10.1080/10168664.2019.1612314

RDSO. (1962). Indian Railway standard code of practice for the design and construction of masonry and plain concrete arch bridges - Arch Bridge Code 6, Lucknow, India .

RDSO. (2008). Bridge rules: Rules specifying the loads for design of super-structure and sub-structure of bridges and for assessment of the strength of existing bridges. Lucknow, India: RESEARCH DESIGNS AND STANDARDS ORGANISATION.

Roselli, I., Malena, M., Mongelli, M., Cavalagli, N., Gioffrè, M., De Canio, G., \& de Felice, G. (2018). Health assessment and ambient vibration testing of the "Ponte delle Torri" of Spoleto during the 2016-2017 Central Italy seismic sequence. Journal of Civil Structural Health Monitoring, 8(2), 199-216. https://doi.org/10.1007/s13349-018-0268-5

Sarhosis, V., De Santis, S., \& de Felice, G. (2016). A review of experimental investigations and assessment methods for masonry arch bridges. Structure and Infrastructure Engineering, 12(11), 1439-1464. https://doi.org/10.1080/15732479.2015.1136655

Sevim, B., Atamturktur, S., Altunişik, A. C., \& Bayraktar, A. (2016). Ambient vibration testing and seismic behavior of historical arch bridges under near and far fault ground motions. Bulletin of Earthquake Engineering, 14(1), 241-259. https://doi.org/10.1007/s10518-015-9810-6

Shimpi, V., Sivasubramanian, M. V. R., \& Singh, S. B. (2019). System identification of heritage structures through AVT and OMA: A review. SDHM Structural Durability and Health Monitoring, 13(1). https://doi.org/10.32604/sdhm.2019.05951

Sun, L., \& Xu, Y. (2020). Modal parameter identification and finite element model updating of a long-span aqueduct structure based on ambient excitation. Journal of Vibroengineering, 22(4), 896-908. https://doi.org/10.21595/jve.2020.21271

Tubaldi, E., Macorini, L., \& Izzuddin, B. A. (2020). Identification of critical mechanical parameters for advanced analysis of masonry arch bridges. Structure and Infrastructure Engineering, 16(2), 328-345. https://doi.org/10.1080/15732479.2019.1655071

Zhang, L., Wang, T., \& Tamura, Y. (2010). A frequency-spatial domain decomposition (FSDD) method for operational modal analysis. Mechanical Systems and Signal Processing, 24(5), 1227-1239. https://doi.org/10.1016/j.ymssp.2009.10.024

Zonno, G., Aguilar, R., Boroschek, R., \& Lourenço, P. B. (2019). Environmental and Ambient Vibration Monitoring of Historical Adobe Buildings: Applications in Emblematic Andean Churches. International Journal of Architectural Heritage, ISSN: 1558-3058, 1-17. https://doi.org/10.1080/15583058.2019.1653402 